and/or survival of NSCs. This may afford some oncogenic insight, as chromosome $1 \mathrm{q}$ gain has been observed in a number of malignancies, and thus may contain genes that increase cell growth capacity regardless of cell lineage.

\section{Implications and future perspectives}

Despite the concerns, one of the fundamental questions to consider is whether the cells studied by Varela and colleagues, as well as other abnormal cells, are always unsuitable for therapy. As mutation is not uncommon during the generation and maintenance of iPS cells $(16,17)$, are these cells and their differentiated derivatives also unfit for clinical use? Clearly NSCs that are unable to differentiate cannot be taken forward to the clinic, but some variant lines were equally capable of terminal differentiation, when derived from either pluripotent cells or fetal tissue. For those variant NSCs capable of generating neurons, but not tumors, it may be argued that culture adaptation has merely created a population of cells that are more readily expandable, and therefore better suited to therapeutic needs. The answer lies in rigorous testing, as the tumorigenic properties of these cells must be addressed if they are to be used in regenerative medicine. Any indications of abnormality in pluripotent cells and their derivatives must then be recorded, as their value in screen- ing, and perhaps better understanding cell behavior, will doubtless help these cells realize their great potential.

\section{Acknowledgments}

The author thanks Peter Andrews for his comments and the Medical Research Council (MRC) for financial support.

Address correspondence to: Neil J. Harrison, Centre for Stem Cell Biology, Department of Biomedical Science, University of Sheffield, Western Bank, Sheffield, S10 2TN, United Kingdom. Phone: 44.114.2222313; Fax: 0114.222.2399; E-mail: N.J.Harrison@sheffield.ac.uk.

1. Zhou J, Su P, Li D, Tsang S, Duan E, Wang F. Highefficiency induction of neural conversion in human ESCs and human induced pluripotent stem cells with a single chemical inhibitor of transforming growth factor beta superfamily receptors. Stem Cells. 2010;28(10):1741-1750.

2. Draper JS, et al. Recurrent gain of chromosomes $17 \mathrm{q}$ and 12 in cultured human embryonic stem cells. Nat Biotechnol. 2004;22(1):53-54.

3. Varela C, et al. Recurrent genomic instability of chromosome $1 \mathrm{q}$ in neural derivatives of human embryonic stem cells. JClin Invest. 2012;122(2):569-574.

4. Faria C, et al. Pediatric brain tumors: genetics and clinical outcome. J Neurosurg Pediatr. 2010; 5(3):263-270.

5. Miwa T, Hirose Y, Sasaki H, Ezaki T, Yoshida K, Kawase T. Single-copy gain of chromosome 1q is a negative prognostic marker in pediatric nonependymal, nonpilocytic gliomas. Neurosurgery. 2011;68(1):206-212.

6. Baker DE, et al. Adaptation to culture of human embryonic stem cells and oncogenesis in vivo. Nat Biotechnol. 2007;25(2):207-215.

7. Ben-David U, Mayshar Y, Benvenisty N. Large-scale analysis reveals acquisition of lineage-specific chromosomal aberrations in human adult stem cells. Cell Stem Cell. 2011;9(2):97-102.

8. Amit $\mathrm{M}$, et al. Clonally derived human embryonic stem cell lines maintain pluripotency and proliferative potential for prolonged periods of culture. Dev Biol. 2000;227(2):271-278

9. Koch P, Opitz T, Steinbeck JA, Ladewig J, Brüstle O. A rosette-type, self-renewing human ES cell-derived neural stem cell with potential for in vitro instruction and synaptic integration. Proc Natl Acad SciUS A. 2009;106(9):3225-3230.

10. Nemati $S$, et al. Long-term self-renewable feeder-free human induced pluripotent stem cellderived neural progenitors. Stem Cells Dev. 2011; 20(3):503-514.

11. The International Stem Cell Initiative et al. Screening ethnically diverse human embryonic stem cells identifies a chromosome 20 minimal amplicon conferring growth advantage. Nat Biotechnol. 2011;29(12):1132-1144

12. Wu W, et al. Long-term cultured human neural stem cells undergo spontaneous transformation to tumorinitiating cells. Int J Biol Sci. 2011;7(6):892-901.

13. Vukicevic V, et al. Genetic instability and diminished differentiation capacity in long-term cultured mouse neurosphere cells. Mech Ageing Dev. 2010;131(2):124-132

14. Diaferia GR, et al. Systematic chromosomal analysis of cultured mouse neural stem cell lines. Stem Cells Dev. 2011;20(8):1411-1423.

15. Sareen D, et al. Chromosome 7 and 19 trisomy in cultured human neural progenitor cells. PLoS One. 2009;4(10):e7630.

16. Gore A, et al. Somatic coding mutations in human induced pluripotent stem cells. Nature. 2011;471(7336):63-67.

17. Hussein SM, et al. Copy number variation and selection during reprogramming to pluripotency. Nature. 2011;471(7336):58-62

\title{
Yes, even human brown fat is on fire!
}

\author{
Barbara Cannon and Jan Nedergaard
}

The Wenner-Gren Institute, Stockholm University, Stockholm, Sweden.

\begin{abstract}
That adult humans possess brown fat is now accepted - but is the brown fat metabolically active? Does human brown fat actually combust fat to release heat? In this issue of the JCI, Ouellet et al. demonstrate that metabolism in brown fat really is increased when adult humans are exposed to cold. This boosts the possibility that calorie combustion in brown fat may be of significance for our metabolism and, correspondingly, that the absence of brown fat may increase our proneness to obesity - provided that brown fat becomes activated not only by cold but also through food-related stimuli.
\end{abstract}

Brown adipose tissue is unique in possessing the ability to directly transfer energy from food into heat (1). This is due to the equally

Conflict of interest: The authors declare that they received support during 2010 from the company Mitotech for unrelated research.

Citation for this article: J Clin Invest. 2012; 122(2):486-489. doi:10.1172/JCI60941. unique ability of its characteristic protein uncoupling protein 1 (UCP1) to allow for combustion of food energy in the brown fat mitochondria. Through this, brown fat produces heat for defense against cold - and may prevent obesity by allowing for combustion of energy, instead of storing the excess energy as fat. Brown adipose tissue has long been accepted as a metabolically important organ in small mammals (rats, mice), but only within the last five years has it been brought forward as a possibly metabolically significant tissue in adult humans.

Anatomically, brown adipose tissue in adult humans is found primarily in depots in the neck and around the clavicles (Figure 1). However, accepting the anatomical presence of the tissue is not the same as accepting that it plays an important metabolic role. Acceptance of brown adipose tissue as a significant factor in the metabolism of adult humans will be a stepwise process. Ouellet et al. (2) provide an important further step in this process. They demonstrate that brown adipose tissue in adult humans is actually metabolically highly active when it is stimulated physiologically, that is, even human brown fat is on fire. 


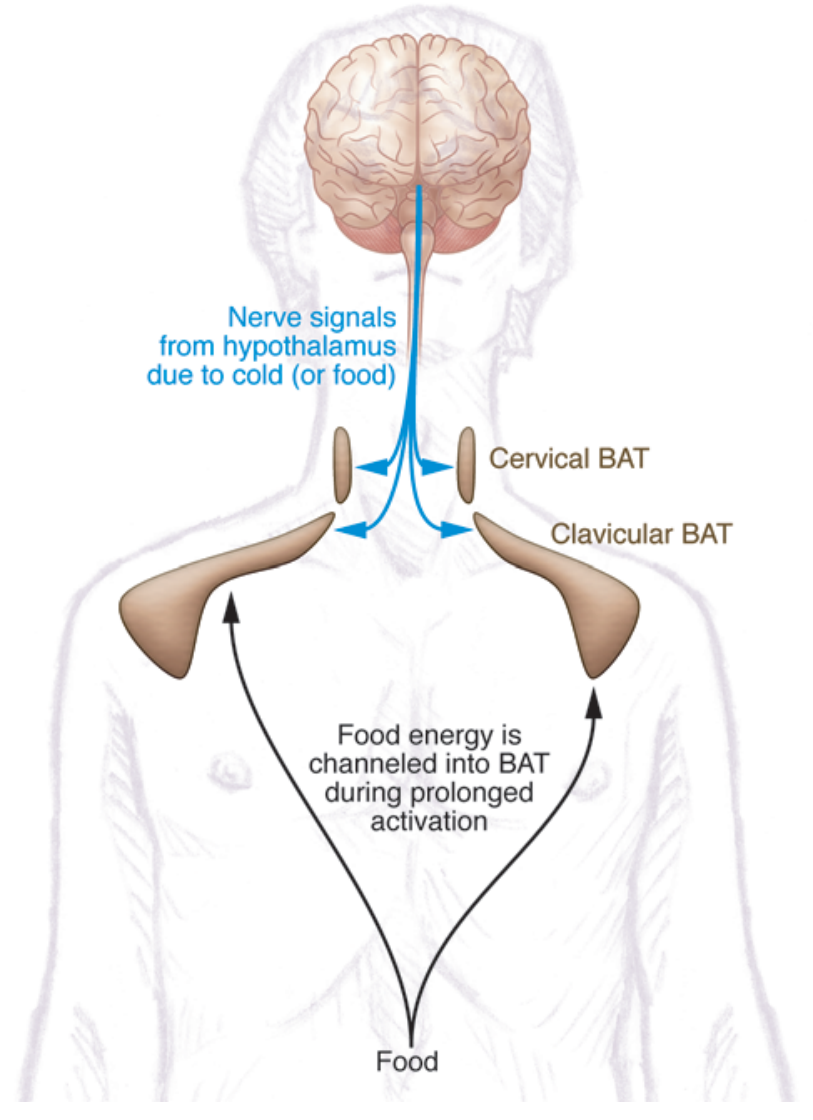

\section{Figure 1}

Location and control of brown adipose tissue in adult humans. Brown adipose tissue (BAT) is mainly found in depots localized below the clavicles and in the neck (but amount and shape may vary considerably). The activity of the tissue is regulated from the brain, based on the need for heat for body temperature control (as investigated here by Ouellet et al.; ref. 2) (thermoregulatory thermogenesis) or also, probably, on the need for metaboloregulatory thermogenesis. The heat results initially from combustion of stored lipid within the brown adipose tissue (Figure 2), but during prolonged thermogenesis, the components of ingested food are channeled to the tissue as a continuous supply of substrate.

\section{The preceding steps}

In the 1990s, enigmatic symmetrical areas of unidentified tissues showing high glucose uptake were observed in routine PET scans of cancer patients (3). As early as 2002 , it was suggested that such areas could represent brown adipose tissue (4), but this realization was buried in journals of radiology and went unrecognized in the metabolic world for half a decade. Even when the radiological treasure of unexpected evidence for the presence of active brown adipose tissue in adult humans was dug out (5), the data suggested that brown adipose tissue was only relevant for a small fraction (perhaps some $2 \%-5 \%$ ) of adults. This apparent low prevalence was, however, due to all studies being "retrospective," in that they were based on hospital records where patients were only unintentionally cold stressed. Later dedicated studies show that at least $30 \%$ of all adults - and probably close to $100 \%$ of young adults - possess brown adipose tissue $(6,7)$.

Acceptance that areas of glucose uptake were depots of brown adipose tissue required demonstration that the tissues contained the brown fat-specific UCP1. Indeed, concordant studies have demonstrated UCP1 mRNA and UCP1 protein in the clavicular and neck areas that show a high glucose uptake (refs. 8, 9, and Figure 1).

However, is this brown adipose tissue really metabolically active: is brown fat on fire even in humans? After all, the indications of activity have until now been based solely on glucose uptake. One indication of increased metabolic activity could be an increased blood flow to the tissue, implying an increased oxygen requirement. Such an increased blood flow has recently been observed in humans in the cold, in parallel with an increase in glucose uptake (10). However, blood flow could increase without a concomitant increase in metabolism.

\section{The present step}

It is here that the paper by Ouellet et al. (2) further advances our understanding. What these authors found is that brown fat activation in the cold is not only associated with increased blood flow, but that it is actually also associated with a higher metabolism in the tissue, i.e., the burning of fat. Ouellet et al. exposed six men to controlled cold (a water-cooled suit). A bolus of radioactive acetate was then given to the subjects. The acetate in the blood will distribute to all tissues, in principle in proportion to the blood flow through the tissue. Already in this respect, brown adipose tissue is remarkable in that the uptake - when the subjects were cold - was some four times higher than that seen in muscle, an indication of a high blood flow to the brown adipose tissue. With the acetate technique, the successive loss of radioactivity from a tissue can be seen as an indication of active metabolism (Figure 2). In cold subjects, Ouellet et al. found that the radioactivity disappeared from the brown adipose tissue with a halflife of just minutes, while the radioactivity remained in the tissue in warm subjects. Thus, the brown adipose tissue really is metabolically active.

\section{From where does the fuel for heat production come?}

Brown adipose tissue has lipid stored in the form of triglyceride droplets (this being the reason that brown adipose tissue has traditionally been classified as being an adipose tissue, rather than being a close relative of muscle, as we think of it today; refs. 11, 12). Consistent with this, data in the paper by Ouellet et al. (2) indicate that during the 3 hours of cold exposure, the main energy came from combustion of lipids stored in the brown adipocytes themselves.

Had the experiment been extended, these stores would have been rapidly depleted, and continued heat production would have been dependent on circulating sources of energy. This could be in the form of circulating free fatty acids from lipid breakdown in white fat. Ouellet et al. demon- 

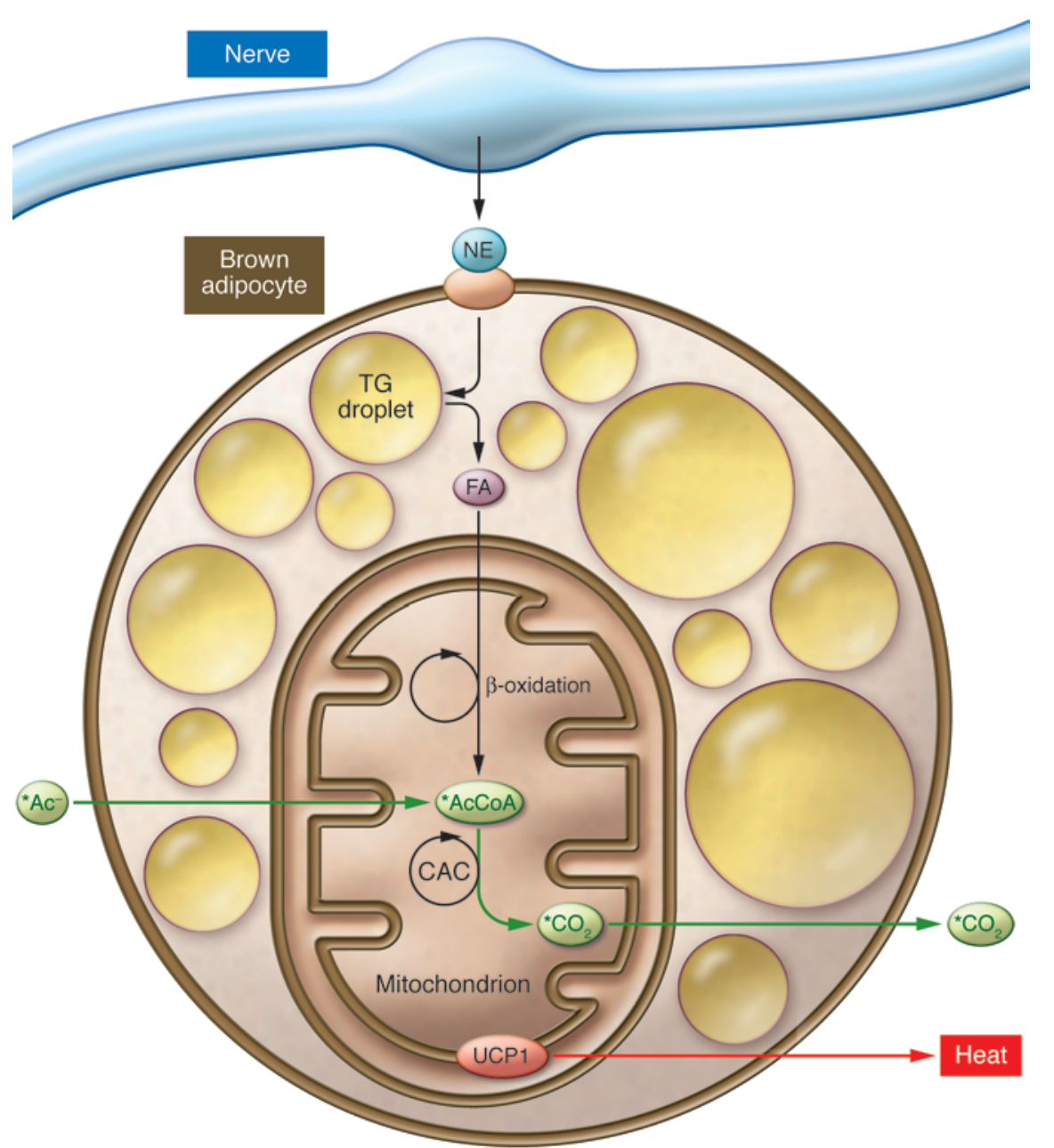

strated such an uptake of fatty acids into brown adipose tissue, but only at a low level. In brown adipose tissue, prolonged heat production is maintained to an even higher degree by uptake by the brown fat cells of circulating triglycerides mediated by the action of lipoprotein lipase, the gene expression of which is much enhanced in the cold (13). Thus, a major fraction of the substrate for combustion in prolonged cold even in humans would probably come from chylomicrons from the gut and from lipoproteins from the liver (14). Additional energy would come from circulating glucose, as can be appreciated from the prominent glucose uptake that led to the original identification of active adult human brown adipose tissue.

\section{Is an $\mathbf{8 0 \%}$ increase in metabolism a lot or a little?}

In the study of Ouellet et al. (2), the subjects exposed to cold stress increased their metabolism by, on average, $80 \%$ over "warm" levels. Some of the heat production undoubtedly emanated from shivering. Ouellet et al. found that shivering in those subjects with the most brown adipose tissue was about half the magnitude of those with less. An interpretation of this would be that about half of the increased heat production resulted from shivering, and about half would be the true contribution of brown adipose tissue (thus, about a $40 \%$ increase over basal). This is slightly higher than but close to results obtained some 30 years ago, in which estimates were made of nonshivering thermogenesis capacity in adult humans, following the strictest protocol for this phenomenon: curarized subjects (i.e., on artificial respiration), who although unable to shiver could still increase their metabolism by some $25 \%$ when exposed to cold (15). Similarly, an increase in metabolism was observed in cold-exposed men, before any shivering was detectable (16). Furthermore, mild cold exposure increas-

\section{Figure 2}

Metabolism in brown adipose tissue. In the cold, the sympathetic nerves from the brain that innervate brown adipose tissue (Figure 1) are active and release norepinephrine (NE), which stimulates the brown fat cells. This leads to activation of triglyceride breakdown and intracellular release of fatty acids (FA). The fatty acids enter the mitochondria and are degraded through $\beta$-oxidation to acetyl-CoA (AcCoA), which enters the citric acid cycle (CAC). Stimulation of the cells by norepinephrine also leads to activation of UCP1, and this allows for the oxidative processes to proceed rapidly, uncoupled from ATP production, i.e., heat is produced. The method used by Ouellet et al. (2) (green) demonstrates increased metabolic activity in brown adipose tissue. $\mathrm{A}$ bolus of positron-labeled $\left({ }^{11} \mathrm{C}\right)$ acetate $\left({ }^{*} A c^{-}\right)$ is injected into the blood and is converted within the cell to acetyl-CoA, which is incorporated into components of the citric acid cycle. When the citric acid cycle rapidly turns over, as happens in stimulated brown fat cells, the labeled carbons are released as $\mathrm{CO}_{2}$, and the positron label is thus lost from the tissue in proportion to the metabolic activity of the tissue. es metabolism in men without leading to observable spontaneous physical activity (non-exercise activity thermogenesis [NEAT]) or to shivering (17). At the time when those experiments were performed, the site of the cold-induced nonshivering thermogenesis was unknown and was definitely not considered to be attributable to brown adipose tissue (since it was believed at that time that adult humans did not possess brown adipose tissue). Today, we can reasonably ascribe all these demonstrations of nonshivering thermogenesis to activation of brown adipose tissue in the examined adult humans.

\section{So, is human brown fat important?}

Given the observations of Ouellet et al. (2), we can now conclude that normal adult subjects possess brown adipose tissue that can be metabolically active. On our stepwise path to acceptance of brown adipose tissue as a significant metabolic factor, what is next? 
One outstanding issue is whether human brown adipose tissue can be physiologically recruited, i.e., does prolonged exposure to an environmental factor such as cold increase the amount and thermogenic capacity of our brown adipose tissue? This would seem to be the case, at least as manifest by a winter/summer difference in the amount of brown adipose tissue in adult humans, when examined in dedicated studies (6) (retrospective studies tend to indicate the same [e.g., ref. 18], but the interpretation of retrospective studies is difficult). However, while a human ability to acclimate to cold by an increased capacity for nonshivering thermogenesis is clearly physiologically interesting, our potential to acclimate to cold is hardly a burning issue in our present civilization.

The interesting issue is, instead, whether the presence or absence (or relative amount) of brown adipose tissue influences our propensity to become obese (and thus our risk of developing obesityrelated comorbidities). A very high negative correlation has been found between obesity and brown adipose tissue amount $(6,7)$. It could arguably be that obesity confers more insulation and therefore obese people possess less brown adipose tissue, although this would imply that the brown adipose tissue that we do possess is primarily a response to experienced cold, perhaps not a major challenge in Western society.

Probably what matters in this respect is our thermogenic response to a meal. Any meal is followed by a "thermogenesis" that has been discussed as consisting of two parts. One is the obligatory component related to the direct handling of the food. The other part (the existence of which has been doubted; ref. 19) is a facultative and possibly even adaptive extra thermogenic component ("diet-induced thermogenesis") that leads to the apparently futile combustion of some of the energy ingested, thus reducing the amount of energy that is stored in the form of fat. This extra thermogenesis may be mediated by brown adipose tissue. Even in humans, there are indications in support of this. Having a genetic polymorphism that is associated with a lower expression of UCP1 leads to a lower thermogenic response to a meal (20). Furthermore, subjects who have been confirmed as possessing brown adipose tissue show a higher thermogenic response to a test meal than subjects without brown adipose tissue, i.e., they convert a higher proportion of the calories in the meal directly to heat than do subjects without brown fat (21).

\section{Can brown adipose tissue be recruited to combat obesity?}

Pharmaceutical companies and academic researchers around the world are attempting to find ways to increase the amount of brown adipose tissue (or just UCP1) in adult humans. The simple thought is this: if we had more brown fat, we would become slimmer. There is, however, at least one important caveat in this line of thought. Studies of isolated brown fat mitochondria (22), isolated brown fat cells, and intact mice all converge on the same conclusion: when not acutely activated, brown adipose tissue does not do anything. This is also the outcome of the study of Ouellet et al. (2). Although the subjects obviously had the same amount of brown adipose tissue when examined under acute cold or warm conditions, the increased brown adipose tissue metabolism was only seen under cold conditions. Thus, what we have to wish for is not only more brown adipose tissue in adult humans - but that it would actually be "on fire" when we eat.

Address correspondence to: Barbara Cannon, Stockholm University, The WennerGren Institute, The Arrhenius Laboratories F3, Stockholm, SE-106 91, Sweden. Phone: 46.8.164120; Fax: 46.8.156756; E-mail: barbara.cannon@wgi.su.se.

\footnotetext{
1. Cannon B, Nedergaard J. Brown adipose tissue: function and physiological significance. Physiol Rev. 2004;84(1):277-359.

2. Ouellet V, et al. Brown adipose tissue oxidative metabolism contributes to energy expenditure during acute cold exposure in humans. J Clin Invest. 2012;122(2):545-552.

3. Barrington SF, Maisey MN. Skeletal muscle uptake of fluorine-18-FDG: effect of oral diazepam. J Nucl
} Med. 1996;37(7):1127-1129.
4. Hany TF, Gharehpapagh E, Kamel EM, Buck A, Himms-Hagen J, von Schulthess GK. Brown adipose tissue: a factor to consider in symmetrical tracer uptake in the neck and upper chest region. EurJ Nucl Med Mol Imaging. 2002;29(10):1393-1398.

5. Nedergaard J, Bengtsson T, Cannon B. Unexpected evidence for active brown adipose tissue in adult humans. Am J Physiol Endocrinol Metab. 2007; 293(2):E444-E452.

6. Saito $M$, et al. High incidence of metabolically active brown adipose tissue in healthy adult humans: effects of cold exposure and adiposity. Diabetes. 2009;58(7):1526-1531.

7. van Marken Lichtenbelt WD, et al. Cold-activated brown adipose tissue in healthy men. $N$ Engl J Med. 2009;360(15):1500-1508.

8. Virtanen KA, et al. Functional brown adipose tissue in healthy adults. N Engl J Med. 2009; 360(15):1518-1525.

9. Zingaretti MC, et al. The presence of UCP1 demonstrates that metabolically active adipose tissue in the neck of adult humans truly represents brown adipose tissue. FASEB J. 2009;23(9):3113-3120.

10. Orava J, et al. Different metabolic responses of human brown adipose tissue to activation by cold and insulin. Cell Metab. 2011;14(2):272-279.

11. Timmons JA, et al. Myogenic gene expression signature establishes that brown and white adipocytes originate from distinct cell lineages. Proc Natl Acad Sci U S A. 2007;104(11):4401-4406.

12. Seale P, et al. PRDM16 controls a brown fat/skeletal muscle switch. Nature. 2008;454(7207):961-967.

13. Mitchell JR, Jacobsson A, Kirchgessner TG, Schotz MC, Cannon B, Nedergaard J. Regulation of expression of the lipoprotein lipase gene in brown adipose tissue. Am J Physiol. 1992;263(3 pt 1):E500-E506.

14. Bartelt A, et al. Brown adipose tissue activity controls triglyceride clearance. Nat Med. 2011; 17(2):200-205.

15. Jessen K, Rabol A, Winkler K. Total body and splanchnic thermogenesis in curarized man during a short exposure to cold. Acta Anaesthesiol Scand. 1980;24(4):339-344.

16. Doi K, Ohno T, Kurahashi M, Kuroshima A. Thermoregulatory nonshivering thermogenesis in men, with special reference to lipid metabolism. Jpn J Physiol. 1979;29(4):359-372.

17. Harris AM, Macbride LR, Foster RC, McCrady SK, Levine JA. Does non-exercise activity thermogenesis contribute to non-shivering thermogenesis? J Therm Biol. 2006;31(8):634-638.

18. Ouellet V, et al. Outdoor temperature, age, sex, body mass index, and diabetic status determine the prevalence, mass, and glucose-uptake activity of 18F-FDG-detected BAT in humans. J Clin Endocrinol Metab. 2011;96(1):192-199.

19. Kozak LP. Brown fat and the myth of diet-induced thermogenesis. Cell Metab. 2010;11(4):263-267.

20. Nagai N, Sakane N, Ueno LM, Hamada T, Moritani $\mathrm{T}$. The $-3826 \mathrm{~A}-->\mathrm{G}$ variant of the uncoupling protein-1 gene diminishes postprandial thermogenesis after a high fat meal in healthy boys. J Clin Endocrinol Metab. 2003;88(12):5661-5667.

21. Saito M, Yoneshiro T, Aita S. Postprandial thermogenesis and brown adipose tissue in humans. Obesity (Silver Spring). 2011;19(suppl 1):S80.

22. Shabalina IG, Ost M, Petrovic N, Vrbacky M, Nedergaard J, Cannon B. Uncoupling protein-1 is not leaky. Biochim Biophys Acta. 2010;1797(6-7):773-784. 